\title{
PROJECT PRIORISATION FOR PORTFOLIO SELECTION BASED ON THE ANALYTIC NETWORK PROCESS
}

\author{
Mónica Garciá-Melón* \\ Universidad Politécnica de Valencia \\ Valencia, Spain \\ E-mail: mgarciam@dpi.upv.es \\ Aida Smith-Perera \\ Universidad Metropolitana \\ Caracas, Venezuela \\ E-mail: asmith@unimet.edu.ve \\ Rocío Poveda-Bautista \\ Universidad Politécnica de Valencia \\ Valencia, Spain \\ E-mail: ropobau@upvnet.upv.es \\ Juan Pascual Pastor-Fernando \\ Universidad Politécnica de Valencia \\ Valencia, Spain \\ E-mail: jppastor@dpi.upv.es
}

\begin{abstract}
Project selection and priorisation in power utilities in Venezuela is a complex problem due to many factors affecting the decision and all actors participating or being affected by it. Project priorisation is a periodical activity that has to be executed at least once a year to adjust company's budget. In this paper a new approach to prioritize project portfolio in an efficient and reliable way is presented. It is based on strategic objectives of the company and multicriteria decision methods.

The paper introduces a rigorous method with acceptable complexity which seeks to assist managers of a big Electrical Company of Venezuela to distribute the annual budget among the possible improvement actions to be conducted on the electrical network of Caracas. A total of 15 network improvement actions grouped into three clusters according to the strategic objectives of the company have been analyzed using the Project Strategic Index (PSI) proposed.
\end{abstract}

The approach combines the use of the Analytic Network Process (ANP) method with the information obtained from the experts during the decision-making process. The ANP method allows the aggregation of the experts' judgments on each of the indicators used into one Project Strategic Index. In addition, ANP is based on utility ratio functions which are the most appropriate for the analysis of uncertain data, like experts' estimations. Finally, unlike the other multicriteria techniques, ANP allows the decision problem to be modeled using the relationships among dependent criteria.

The participating experts coincided in the appreciation that the method proposed in this paper is useful and an improvement from traditional budget distribution techniques. They find the results obtained

${ }^{*}$ Corresponding author 
coherent, the process seems sufficiently rigorous and precise, and the use of resources is significantly less than in other methods.

Keywords: Analytic Hierarchy Process, Analytic Network Process, power distribution network

\section{Introduction}

The electric power system of Venezuela includes major aspects such as electric power generation, transmission and distribution; since 2007 it has been managed by 11 companies that are financed by the Government of Venezuela. These companies constitute the National Electric Power System (NEPS), which supplies electric power to more than $98 \%$ of the country. http://www.opsis.org.ve. From the 11 companies belonging to NEPS, the seven companies that are exclusively electric power supply companies are affiliates of the National Electric Power Corporation (Corpoelec).

More than $60 \%$ of NEPS' electric power is generated in the south-east of the country, and the energy is transported through the power transmission or distribution system to the north, west and middle of the country using $765 \mathrm{kV}$ $230 \mathrm{kV}$ distribution lines.

In the 1960s several large power generation facilities were built in the south east of the country that harnessed the potential energy from two important rivers, namely the Orinoco and the Caroni. With the development of these electric power plants the power transmission network was extended to other areas of the country because, although the so-called Basic Companies of steel, iron and other metals were located in the south-east of the country, the industrial areas were located in the north and in the central regions of Venezuela and thus it was necessary to develop transmission and distribution lines to meet the power needs of the users using the excess of electric energy generated in the south-east power plants. The power distribution network grew in a disorganized manner, responding with great delay to the increasing power demand. And this is still the situation.

The development, distribution and management of the electric power network and electric companies was very different until the end of 2006 due to aspects as diverse as the stock market, political factors, private interests and the administrative requirements of certain regions. All this led to significant differences in the power distribution system that still today can be clearly observed.

The Electric Power Supply Company of Caracas (EDC) covers about $10 \%$ of the national electric power demand and supplies electricity to Caracas and surrounding area. It is owned now by the stated owned PDVSA (Venezuelan Oil Company).

Table 1 shows EDC's power generation, power capacity and power demand data

\begin{tabular}{|l|c|c|}
\cline { 2 - 3 } \multicolumn{1}{c|}{} & Units & Year 2007 \\
\hline Power capacity & MW & 2,156 \\
\hline Generated power & GWh & 11,039 \\
\hline Exchanged power & GWh & 2,214 \\
\hline Supplied power & GWh & 13,252 \\
\hline Maximum power demand & MW & 2,093 \\
\hline
\end{tabular}

Table 1. General data of EDC's power network

EDC managers have to distribute the annual budget among the different improvement actions to be conducted on the power network system. The budget is divided into two main aspects: expenses and investment. The expenses budget includes periodical activities such as preventive and corrective maintenance services, acquisition of tools and components, wage compensations, long-period contracts and services. On the other hand, the investment budget 
covers the execution of improvement projects. Annually, expenses and investments are planned based on the budget of the previous year.

An important part of the annual budget is assigned to the improvement project plans that will result in a better performance and efficiency of the system as well as in a better power quality for the end users. The improvement project portfolio emerges as a response to the fact that the electric power network itself and its operation have problems and that these problems can be identified and solved. The selection and justification of the periodical activities and project portfolio by the company's management body is a task that has to be done every year. At present, the selection and justification processes are based on experience and intuition.

The need for a reliable and unbiased portfolio selection (investment budget) took the EDC's management body to ask the authors of this work to prioritize the project portfolio.

\section{The use of MCDA techniques for portfolio selection}

Portfolio selection is a challenging task that involves providing an organization with a prioritized list of projects, which will have futuristic scope, strategic fit and stakeholder involvement. These projects should lead the organization to competitiveness and success.

Authors like [Meade, 2002] have indicated the importance of accurately modeling reality when making decisions on allocation of resources that will affect the competitiveness of a firm in one way or another. MCDA techniques are very appropriate to solve this type of problems. The expression MCDA is used as an umbrella term to describe a number of formal approaches which seek to take explicit account of multiple criteria in helping individuals or groups explore decisions that matter [Belton, 2002]. More information about MCDA can be found in [Belton, 2002], [Barba-Romero, 2007].

Several authors have recently introduced the use of MCDA techniques in Project Portfolio Selection. Most of these studies focus on building decision models and developing decision-making methods. Many of them use the Analytic Hierarchy Process [Saaty, 1996] which has been accepted as a leading multi-criteria decision model [Tavana, 2006], [Lee et al., 2009], [Su and Chou, 2008] to assign priorities to the criteria or indicators involved. Others introduce the use of outranking techniques such as Electre [Roy, 1996] and Promethee [Brams et al., 1986] in order to avoid the compensation problem of the traditional methods [Buchanan and and Vanderpooten, 2007], [Halouani et al., 2009]. This compensation or trade-off problem is inherent to all aggregation methods based on sums: an extreme value of one criterion may compensate the moderate values of other criteria giving a global result that may not correspond to the experts' opinion. All these MCDA techniques work well under the assumption of the independence of criteria. However, this assumption is not always realistic and, for sure, not in the field of Strategic Portfolio Selection where multiple related dimensions of information have to be considered in the analysis. Thus, bias can occur when using any of these methods and this can lead to non-optimal evaluations. For that reason, the Analytic Network Process (ANP) is chosen as it takes into account the interdependence among the criteria and avoids to a great extent the problem of compensation.

The Analytic Network Process (ANP) is a method proposed by Saaty. It provides a framework for dealing with decision making or evaluation problems. It presents its strengths when working in scenarios with scarce information. Similar to the AHP, the ANP is based on deriving ratio-scale measurements to be used to allocate resources according to their ratio-scale priorities, whereas ratio-scale assessments, in turn, enable considerations based on trade-offs [Keeney, 1976]. AHP models assume a top-down relationship among decision levels, which means that bias could occur when the criteria and subcriteria are correlated with each other. However, ANP does not require this strictly hierarchical structure and allows for more complex inter-relationships among the decision levels. ANP generalizes the problem modeling process using a network of criteria and alternatives (all called elements), grouped into clusters. All the elements in the network can be related in any possible way, i.e. a network can incorporate feedback and interdependence relationships within and between clusters. This provides an accurate modeling of complex settings and allows handling the usual situation of interdependence among elements in project evaluation scenarios.

Some of the most recent applications involving ANP in the field of Project Management are found in construction project selection [Cheng 2005]; resource allocation in transportation [Wey, 2007]; strategic policy planning 
[Erdogmus, 2006]; strategic e-business decision analysis [Raisinghani, 2007]; determination of the appropriate energy policy [Haktanirlar, 2005] or financial crisis forecasting [Niemira, 2004].

It is very important to count on the participants involved throughout the evaluation and interpretation processes and use of the results. Therefore, the aim of this proposal is not to substitute the work of any of the management team members but on the contrary to ease and facilitate it. The experts' opinions and judgments are the only ones to be taken into account and to be the input data in the evaluation model.

\section{Theoretical background of the ANP model}

Details on the Analytic Network Process (ANP) can be found in Saaty (1996), however, the main steps are summarized here for completeness.

(i) Pairwise comparisons on the elements and relative weight estimation

(ii) Construction of the original supermatrix (unweighted supermatrix).

(iii) Constructing the weighted supermatrix

(iv) Calculation of the global priority weights

\section{Case study: portfolio selection in the company EDC (Venezuela)}

EDC's management body asked for advice to the authors of this work on the process of prioritizing project portfolio selection for annual budget planning for 2008 .

\subsection{Problem formulation}

In a first meeting with the EDC managers a list of common problems in the electric power system that may affect the end users in Caracas was elaborated. In the list it was indicated which problems affected the power distribution network and its operation as a whole and which problems affected only some sections of the power system (voltage, geographical location etc). After the elaboration of the list, the managers presented feasible solutions (periodical activities and projects) to the problems; in this way, the problems were formulated as power network improvement action plans, and future network operation and maintenance services were determined. This first meeting served as a face-to-face discussion and brainstorming.

As a result, a total of 47 problems and their possible corrective actions were identified. This list was further reviewed and reduced to 15 (repeated problems or incomprehensive problems were removed from the list, according to the experts' answers)

\subsection{The alternatives}

The EDC's experts divided the final list of improvement projects or action plans into three groups according to the three strategic goals of the company, since the execution of the actions of each group have to be performed by different actors. This grouping into three categories greatly facilitates the process of project portfolio prioritization from different points of view: i) prioritizing the set of 15 actions taking into consideration all the criteria; ii) prioritizing the list of actions by typology; and iii) overall estimation of the impact of each category in comparison to the other categories

On the other hand, according to Saaty [Saaty,1980], it is not recommendable to work with clusters of more than 9 elements because many pairwise comparisons would result in high inconsistency judgment ratios. For this reason we decided to divide the project portfolio into three groups according to the three strategic goals of the company.

The selected alternatives and the three groups were:

Human resources

A1. Increase head count

Dependence on contractors for the development of periodical works is inefficient; therefore, in some priority areas these works have to be done by the company's workers, who at this moment are insufficient in number (Increase head count)

A2. Improvement in the contractors' service and follow up 
This alternative involves determining the follow up mechanisms to supervise the contractors' service and develop legal mechanisms to penalize and, if necessary, to cancel the contracts (Contractors' service)

A3. New technology training

In order to improve network performance new automation technologies must be implemented and the staff trained (New technology training)

A4. Re-establish the training center for electricity technicians.

The electricity technicians developing field work only have elementary electrical training that is inefficient and insufficient. The objective is to re-open the old training centres for electricity technicians that were supervised by the electric power companies and provided appropriate electrical training (Electrical training)

\section{A5. Simplify hiring processes}

Hiring processes are slow and complex and involve unnecessary and cumbersome extra work (Simplify hiring processes)

$\underline{\text { Technical }}$

A6. Improve circuit planning in order to lower disconnected load when failures.

The circuit planning units of the distribution network must work jointly with the operational units in order to reduce disconnected loads when service failures, outages or interruptions occur. (Lower disconnected load)

\section{A7. Elimination of illegal network connections.}

Illegal network connections technically affect service quality of the distribution network and users. The causes must be identified and solved (Illegal connections)

\section{A8. Tie Switches equipment automation.}

Circuit transfer equipment should be automated to allow circuit transfers to nearby circuits. Circuit transfers are calculated and the data input for recovery of load losses due to system failure or maintenance operations (Circuit transfer automation)

\section{A9. Network automation}

Network automation improves system robustness as it allows load re-connection after network failures. Part of the automation process involves data recording and remote data sending to real-time control systems (Network automation)

\section{A10. Locking access to basements and underground facilities}

Access to basements and underground facilities are broken or left open by the workers causing maintenance and servicing problems. A control system must be installed that ensures that the facilities accesses remain locked after maintenance works (Locking basements access)

Quality

A11. Reduce interruption solution time

Failure detection, identification, control and solution times add to the overall failure solution time. Detailed study should be carried out to identify how long it takes to solve the different kinds of network failures (Solution time)

A12. Reduce materials and equipment supply time

The new materials and equipment acquisition procedures that were regulated after the purchase of EDC by the Venezuelan Government modify the traditional procedure for materials and equipment acquisition and hiring. It is necessary to understand and optimize them. (Supply time)

\section{A13. Increase customer satisfaction}

End users can be classed as large or small power consumers. The expectations of each group are different; hence the actions aimed at improving customer satisfaction ratios are also different and must be adapted to meet the specific needs of each group (Customer satisfaction)

\section{A14. Improve contract awarding internal processes}


Contract awarding for routine or emergency services is affected by project tendering and hiring legal regulations. The internal hiring processes require revision and improvement to reduce hiring process times without detriment of tendering quality (Contract awarding)

\section{A15. Reduce failure trip time}

Failure trip times, as a part of failure times, as well as claim attention times are affected by city traffic; however it is necessary to find ways of reducing trip times (Failure trip time)

\subsection{Selection of the criteria}

In the same work meeting where the company's managers had to identify the project alternatives, they also were asked to list the criteria for improvement projects prioritization. They called them key indicators. The following list was obtained:
C01. Service continuity
C02. Service quality
C03. Costs
C04. Investment
C05. Execution feasibility
C06. Customers' satisfaction
C07. Staff satisfaction
C08. Network flexibility
C09. Maintenance and servicing plans
C10. Response time

\subsection{Representation of the evaluation problem as a network model}

The complex task of representing the evaluation problem as a network of interdependent elements distributed into clusters can be broken down into the following steps: (i) to identify the elements (alternatives and criteria), (ii) to group them into clusters and (iii) to determine the influences on each other.

For our case study the following network with four clusters has been built: the alternatives grouped into three clusters and the criteria grouped into one cluster. The four clusters and their inter-relationships are shown in Figure 1 .

The five alternatives were grouped into three clusters. One cluster is related to the Human Resources actions (including staff training and hiring improvement actions); another cluster deals with the quality actions (including service quality and improvement actions); and the third cluster deals with technical actions (including network improvement actions). The fourth cluster contains the ten criteria mentioned earlier in this paper.

The two-way arrows indicate bi-directional influences between clusters, i.e. the criteria exert some influence on the alternatives so that the criteria have to be weighted in order to estimate their contribution to the alternatives value. On the other hand, inverse influence means that the alternatives have to be weighted in order to measure their dominance with respect to each criterion. Feedback means that there is influence among the elements within a cluster. For example, the element Illegal connections depends on the element Contractors'service.

\subsection{Solution of the ANP project evaluation problem. Calculation of the PSI indices}

The aim of this step is to obtain an Index for each alternative which indicates the degree of achievement of the strategic goals regarding all the criteria considered. The higher the value of the index the better the proposal is.

A sample of the questionnaire designed to answer all the necessary pairwise questions, is shown below:

\begin{tabular}{|l|c|c|c|c|c|}
\hline & $C 1 \quad X$ & $C 2$ & \multicolumn{4}{|c|}{9} \\
\hline To what extent? & 1 & $3 \quad X$ & 5 & 7 & 9 \\
\hline
\end{tabular}

Table 3. Sample of the ANP questionnaire 
In order to alleviate the mathematical burden the following calculations were implemented through the software Superdecisions ${ }^{(}$. Upon completion of all pairwise comparison matrices, the unweighted supermatrix is built. Results are shown on Table 4.

The corresponding priorities of the clusters have been obtained and used to weight this matrix, shown on table 5 .

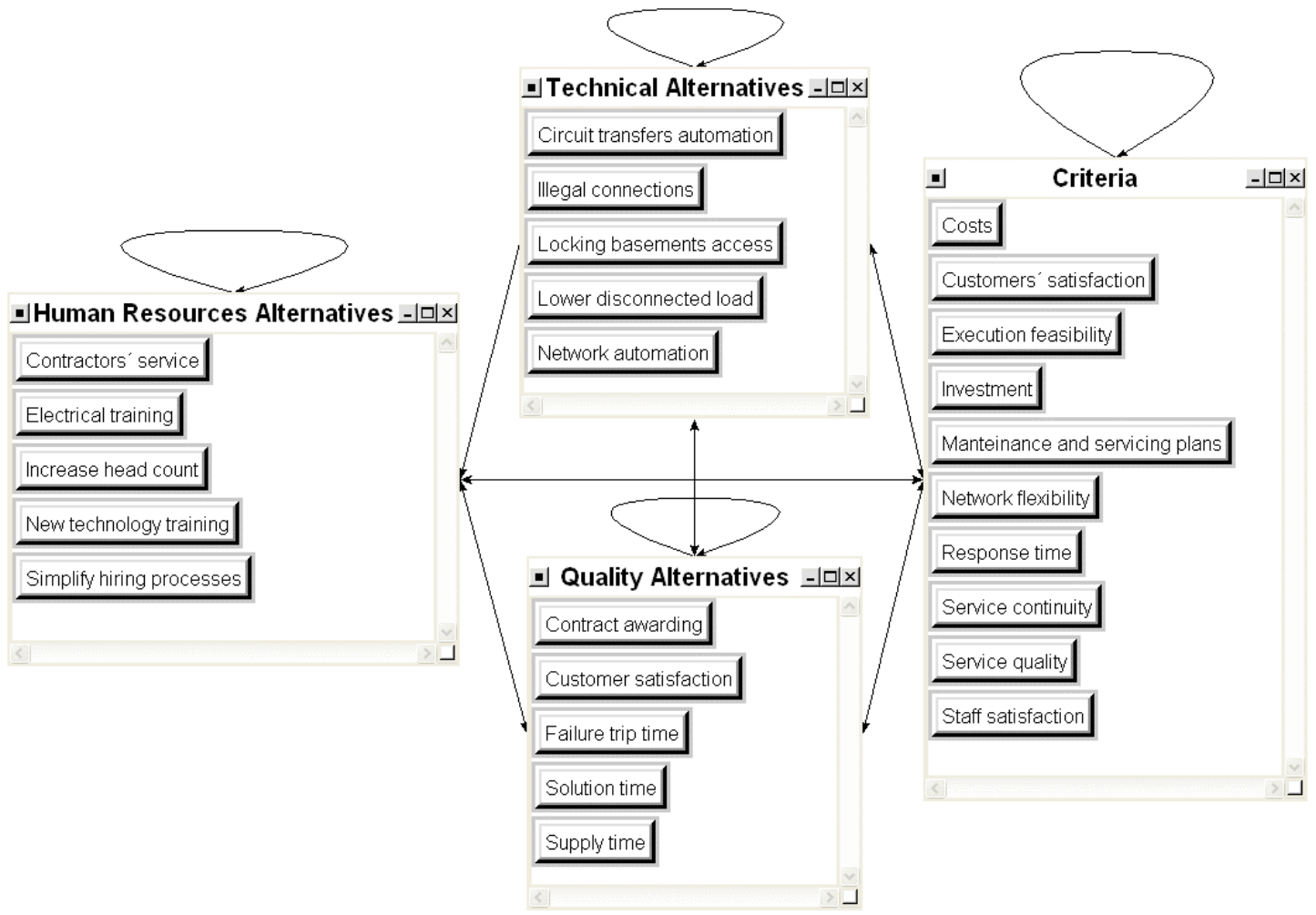

Figure 1. Network model for the case study

Raising the weighted supermatrix to limiting powers until the weights converge and remain stable the limit supermatrix will be achieved. Since all the columns of this last matrix are the same, only the resulting values of one column are shown in Table 6 due to space constraints.

\begin{tabular}{|c|c|c|c|c|c|c|c|c|c|c|c|c|c|c|c|c|c|c|c|c|c|c|c|c|c|c|}
\hline & \multicolumn{5}{|c|}{ Human Resources } & \multicolumn{5}{|c|}{ Technical } & \multicolumn{5}{|c|}{ Quality } & \multicolumn{10}{|c|}{ Criteria } \\
\hline & & $\mathrm{A} 1$ & $\mathrm{~A} 2$ & A3 & A4 & A5 & A6 & A7 & A8 & A9 & A10 & A11 & A12 & A13 & A14 & A15 & $\mathrm{C} 01$ & $\mathrm{CO} 2$ & $\mathrm{CO3}$ & $\mathrm{CO4}$ & $\cos$ & $\mathrm{C} 06$ & $\mathrm{C} 07$ & $\mathrm{C} 08$ & $\mathrm{cos}$ & $\mathrm{C} 10$ \\
\hline \multirow{5}{*}{ 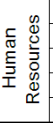 } & A1 & 0 & 0 & 0,5 & 0 & 1 & 0,161 & 0,469 & 0 & 0 & 0 & 0,128 & 0 & 0,124 & 0 & 0 & 0,168 & 0 & 0 & 0 & 0 & 0 & 0 & 0,111 & 0,096 & 0 \\
\hline & A2 & 0 & 0 & 0 & 0 & 0 & 0,240 & 0,531 & 0 & 0 & 0 & 0,142 & 0 & 0,275 & 1 & 0 & 0,278 & 0,573 & 0 & 0,260 & 0 & 0,182 & 0,888 & 0,067 & 0,224 & 0,274 \\
\hline & A3 & 0,25 & 0,5 & 0 & 0,125 & 0 & 0,240 & 0 & 0 & 0 & 0 & 0,198 & 0 & 0,066 & 0 & 0 & 0,033 & 0 & 0 & 0,308 & 0 & 0,126 & 0 & 0,111 & 0 & 0 \\
\hline & A4 & 0 & 0,5 & 0 & 0 & 0 & 0,359 & 0 & 0 & 0 & 0 & 0,437 & 0 & 0,441 & 0 & 0 & 0,521 & 0,427 & 0 & 0,432 & 0 & 0,693 & 0,112 & 0,287 & 0,295 & 0,726 \\
\hline & A5 & 0,75 & 0 & 0,5 & 0,875 & 0 & 0 & 0 & 0 & 0 & 0 & 0,096 & 0 & 0,094 & 0 & 0 & 0 & 0 & 0 & 0 & 0 & 0 & 0 & 0,424 & 0,385 & 0 \\
\hline \multirow{5}{*}{ 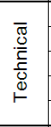 } & A6 & 0 & 0 & 0 & 0 & 0 & 0 & 0 & 0 & 0 & 0 & \begin{tabular}{|l|l|}
0,143 \\
\end{tabular} & 0 & 0,153 & 1 & 1 & 0,255 & 0 & 0 & 0,302 & 0 & 0 & 0,565 & 0,191 & 0,417 & 0,094 \\
\hline & \begin{tabular}{|l|} 
A7 \\
\end{tabular} & 0 & 0 & 0 & 0 & 0 & 0,059 & 0 & 0 & 0 & 0 & 0 & 0 & 0,284 & 0 & 0 & 0 & 0 & 0 & 0 & 0 & 0,095 & 0,067 & 0,427 & 0,057 & 0 \\
\hline & A8 & 0 & 0 & 0 & 0 & 0 & 0,297 & 0 & 0 & 0 & 0 & 0,571 & 0 & 0,065 & 0 & 0 & 0,279 & 0,346 & 0,152 & 0,239 & 0,274 & 0,313 & 0,167 & 0,191 & 0 & 0,307 \\
\hline & \begin{tabular}{|l|} 
A9 \\
\end{tabular} & 0 & 0 & 0 & 0 & 0 & 0,644 & 1 & 0 & 0 & 1 & 0,286 & 0 & \begin{tabular}{|l|}
0,086 \\
\end{tabular} & 0 & 0 & 0,131 & 0,112 & 0,216 & 0,410 & 0,726 & 0,494 & 0,091 & 0,191 & 0,368 & 0,508 \\
\hline & A10 & 0 & 0 & 0 & 0 & 0 & 0 & 0 & 0 & 0 & 0 & 0 & 0 & 0,412 & 0 & 0 & 0,335 & 0,542 & 0,632 & 0,048 & 0 & 0,098 & \begin{tabular}{|l|}
0,110 \\
\end{tabular} & 0 & 0,158 & 0,092 \\
\hline \multirow{5}{*}{$\begin{array}{l}\frac{\bar{\Xi}}{\tilde{\sigma}} \\
\vec{\sigma}\end{array}$} & A11 & 0 & 0 & 0 & 0 & 0 & 0,067 & 0,112 & 0 & 0 & 0 & 0 & 0 & 0 & 0,274 & 0,542 & 0,084 & 0 & 0 & 0 & 0 & 0,046 & 0,461 & 0,057 & 0,046 & 0,028 \\
\hline & A12 & 0 & 0,152 & 0 & 0 & 0 & 0,467 & 0,888 & 0 & 0 & 0 & 0,247 & 0 & 0,274 & 0,726 & 0 & 0,742 & 0,299 & 0 & 0,25 & 0,291 & 0,336 & 0,222 & 0,580 & 0,331 & 0,408 \\
\hline & A13 & 1 & 0,291 & 0 & 1 & 0 & 0 & 0 & 0 & 0 & 0 & 0,306 & 0 & 0 & 0 & 0,458 & 0,081 & 0 & 0,5 & 0 & 0,067 & 0,042 & 0,132 & 0,057 & 0,286 & 0,072 \\
\hline & A14 & 0 & 0 & 0 & 0 & 0 & 0,467 & 0 & 0 & 0 & 0 & 0 & 1 & 0,726 & 0 & 0 & 0 & 0,649 & 0,5 & 0,75 & 0,641 & 0,517 & 0,117 & 0 & 0 & 0,408 \\
\hline & A15 & 0 & 0,557 & 0 & 0 & 0 & 0 & 0 & 0 & 0 & 0 & 0,447 & 0 & 0 & 0 & 0 & 0,093 & 0,052 & 0 & 0 & 0 & 0,059 & 0,069 & 0,306 & 0,337 & 0,084 \\
\hline \multirow{10}{*}{ 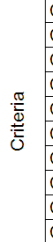 } & Co1 & 0,047 & 0 & 0 & 0 & 0 & 0 & 0 & 0 & 0 & 0 & 0 & 0 & 0 & 0 & 0 & 0 & 0 & 0 & 0 & 0 & 0 & 0,111 & 0 & 0 & 0 \\
\hline & $\mathrm{CO2}$ & 0,085 & 0 & 0 & 0 & 0 & 0,033 & 0,063 & 0 & 0 & 0 & 0,027 & 0 & 0,066 & 0 & 0 & 0,387 & 0 & 0 & 0 & 0 & 0 & 0,385 & 0 & 0 & 0 \\
\hline & $\mathrm{CO3}$ & 0 & 0,500 & 0,635 & 0,556 & 0 & 0,188 & 0,753 & 0,304 & 0,304 & 0 & 0,160 & 0,274 & 0,209 & 0 & 0 & 0,201 & 0,078 & 0 & 0,5 & 0 & 0,315 & 0 & 0 & 0,644 & 0 \\
\hline & CO4 & 0 & 0 & 0 & 0 & 0 & 0 & 0 & 0,063 & 0,063 & 0 & 0,021 & 0 & 0 & 0 & 0 & 0,021 & 0,022 & 0 & 0 & 0 & 0 & 0 & 0,068 & 0 & 0 \\
\hline & C05 & 0,382 & 0,500 & 0 & 0,338 & 0,112 & 0,394 & 0 & 0,633 & 0,633 & 0 & 0,114 & 0,726 & 0,189 & 0 & 0,5 & 0,067 & 0,203 & 0 & 0,5 & 0 & 0,333 & 0 & 0 & 0,297 & 0 \\
\hline & C06 & 0,074 & 0 & 0 & 0 & 0 & 0,088 & 0 & 0 & 0 & 0 & 0,093 & 0 & 0,087 & 0 & 0 & 0,050 & 0,213 & 0 & 0 & 0 & 0 & 0 & 0,308 & 0,059 & 0 \\
\hline & COT & 0 & 0 & 0,050 & 0 & 0 & 0 & 0 & 0 & 0 & 0 & 0 & 0 & 0,028 & 0 & 0 & 0 & 0 & O & 0 & 0 & 0 & 0 & 0 & 0 & 0 \\
\hline & C08 & 0,277 & 0 & 0,240 & 0,051 & 0 & 0 & 0 & 0 & 0 & 0 & 0,181 & 0 & 0 & 0 & 0 & 0 & 0 & 0 & 0 & 0 & 0 & 0,030 & 0 & 0 & 0 \\
\hline & \begin{tabular}{|l|}
$\operatorname{cog}$ \\
\end{tabular} & 0 & 0 & 0 & 0 & 0 & 0,232 & 0 & 0 & 0 & 0 & 0,071 & 0 & 0,376 & 0 & 0 & 0,273 & 0,432 & 0 & 0 & 0 & 0,352 & 0 & 0,624 & 0 & 0 \\
\hline & C10 & 0,135 & 0 & 0,075 & 0,055 & 0,888 & 0,064 & 0,184 & 0 & 0 & 0 & 0,334 & 0 & 0,045 & 0 & 0,5 & 0 & 0,052 & 0 & 0 & 0 & 0 & 0,474 & 0 & 0 & 0 \\
\hline
\end{tabular}


Table 4. Unweighted supermatrix for the case study

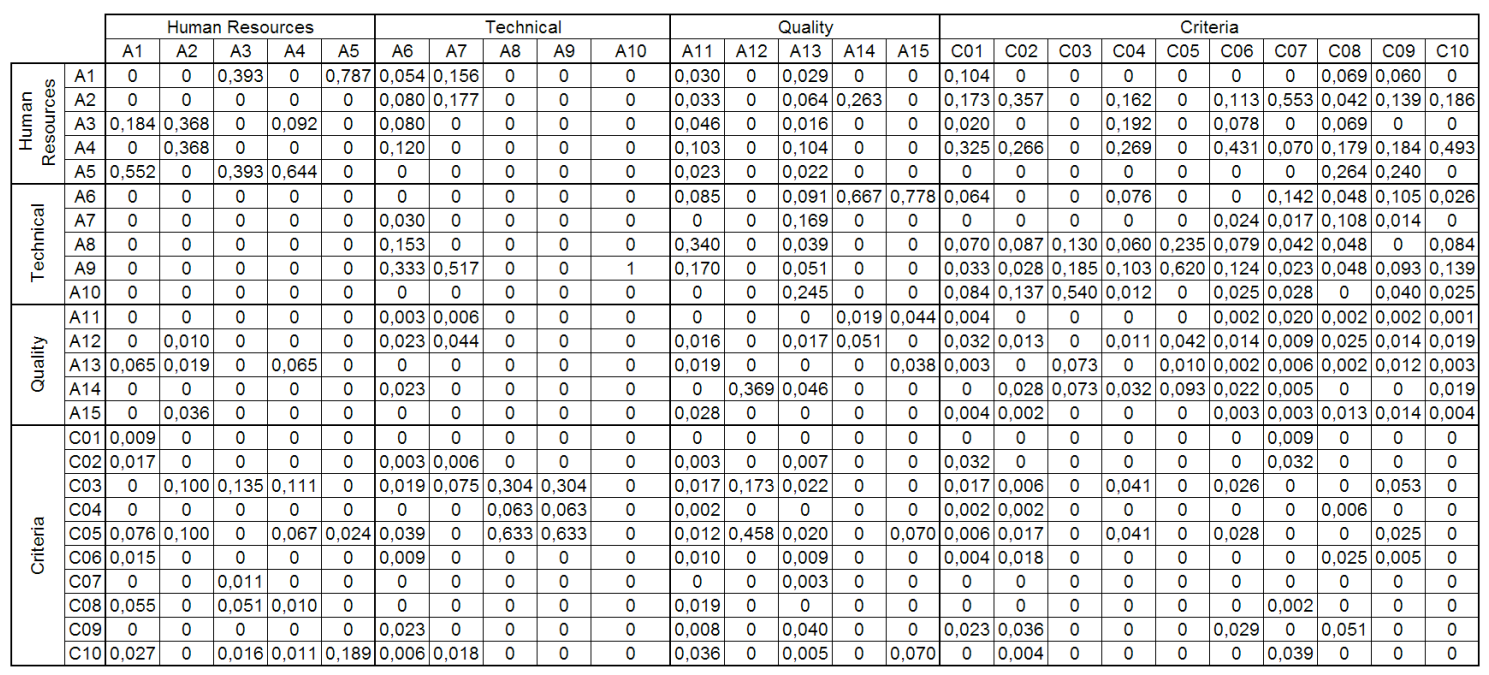

Table 5. Weighted supermatrix for the case study

\begin{tabular}{|c|c|c|c|c|c|c|c|c|c|c|c|c|c|c|}
\hline \multicolumn{15}{|c|}{ Alternatives } \\
\hline \multicolumn{5}{|c|}{ Human Resources } & \multicolumn{5}{|c|}{ Technical factors } & \multicolumn{5}{|c|}{ Quality } \\
\hline A1 & A2 & A3 & A4 & A5 & A6 & A7 & A8 & A9 & A10 & A11 & A12 & A13 & A14 & A15 \\
\hline 0.0696 & 0.0199 & 0.0291 & \begin{tabular}{|l}
0.0277 \\
\end{tabular} & 0.0700 & 0.0263 & 0.0042 & 0.0678 & 0.2182 & 0.0590 & 0.0008 & 0.0121 & \begin{tabular}{|l|l}
0.0160 \\
\end{tabular} & 0.0326 & 0.0009 \\
\hline
\end{tabular}

\begin{tabular}{|c|c|c|c|c|c|c|c|c|c|}
\hline \multicolumn{10}{|c|}{ Criteria } \\
\hline C01 & C02 & C03 & C04 & C05 & C06 & C07 & C08 & C09 & C10 \\
\hline 0.0007 & 0.0014 & 0.1002 & 0.0180 & 0.1997 & 0.0016 & 0.0004 & 0.0056 & 0.0017 & 0.0163 \\
\hline
\end{tabular}

Table 6. Values of one column of the limit supermatrix for the case study

\section{Results}

Several results can be obtained by careful analysis of these matrices.

\subsection{Results about the alternatives}

The priority of each alternative is a non-dimensional value that will be considered the Project Strategic Index (PSI). This global priority can be obtained from the values in any of the columns relative to the alternatives.

\begin{tabular}{|l|c|c|}
\hline \multicolumn{1}{|c|}{ Alternatives } & Priority limit matrix & PSI \\
\hline Increase head count & 0.0696 & $\mathbf{0 . 1 0 6 4}$ \\
\hline Contractors' service & 0.0199 & $\mathbf{0 . 0 3 0 4}$ \\
\hline New technology training & 0.0291 & $\mathbf{0 . 0 4 4 4}$ \\
\hline Electrical training & 0.0277 & $\mathbf{0 . 0 4 2 4}$ \\
\hline Simplify hiring processes & 0.0700 & $\mathbf{0 . 1 0 7 0}$ \\
\hline Lower disconnected load & 0.0263 & $\mathbf{0 . 0 4 0 2}$ \\
\hline Illegal connections & 0.0042 & $\mathbf{0 . 0 0 6 4}$ \\
\hline Circuit transfer automation & 0.0678 & $\mathbf{0 . 1 0 3 7}$ \\
\hline Network automation & 0.2182 & $\mathbf{0 . 3 3 3 4}$ \\
\hline Locking basements access & 0.0590 & $\mathbf{0 . 0 9 0 2}$ \\
\hline Solution time & 0.0008 & $\mathbf{0 . 0 0 1 3}$ \\
\hline
\end{tabular}




\begin{tabular}{|l|l|l|} 
Supply time & 0.0121 & $\mathbf{0 . 0 1 8 5}$ \\
\hline Customer satisfaction & 0.0160 & $\mathbf{0 . 0 2 4 5}$ \\
\hline Contract awarding & 0.0326 & $\mathbf{0 . 0 4 9 9}$ \\
\hline Failure trip time & 0.0009 & $\mathbf{0 . 0 0 1 4}$ \\
\hline
\end{tabular}

Table 7. Results obtained for the alternatives

Which means:

$$
\begin{aligned}
& P S I_{\text {Increase head count }}=0.1064 \\
& P S I_{\text {Improvement in the contractors' service and follow up }}=0.0304 \\
& P S I_{\text {New technology training }}=0.0444
\end{aligned}
$$

And so on

As stated above, a high PSI means a higher achievement of the strategic goals.

The PSI indicates project prioritization and the optimization of the contribution of these projects as a whole to EDC strategic policies.

Due to limited financial resources, the decisions of EDC managers prevailed because of the difficulty in allocating a low budget over multiple periods. The PSI order indicates project selection prior to investment according to these ten criteria.

The results show that the action with the highest Project Strategic Index is Network automation and far down we can find four similarly rated alternatives: Simplify hiring processes, Increase head count, Circuit transfers equipment automation and Lock access to basements and underground facilities. The rest of the alternatives obtain very low PSI values. Thus it can be concluded that there are two types of alternatives: those that obtain relatively high PSI values and those with intermediate PSI values.

According to the experts this first ranked action can be due to the disorganized increasing of the electrical network responding with great delay to the increasing power demand. There has not been enough time to update the complete network. It seems also logical that some of the actions with the highest PSI belong to the cluster "Human Resources" since the power company has changed from private to public and now is an affiliate of the Venezuelan government. This has forced EDC to adapt its human resources policies.

However, since the alternatives rated in the second position obtain similar PSI results, it would be necessary to further analyze intermediate results.

Cluster analysis

During the process of alternatives evaluation the experts were also asked about their judgments on the

\begin{tabular}{|c|c|c|c|c|c|}
\hline & \multicolumn{3}{|c|}{ Alternatives } & \multirow{2}{*}{ Criteria } \\
\hline & & Human Resources & Technical & Quality & \\
\hline \multirow{3}{*}{ Alternatives } & Human Resources & 0.736 & 0.334 & 0.235 & 0.623 \\
\hline & Technical & 0.000 & 0.517 & 0.595 & 0.252 \\
\hline & Quality & 0.065 & 0.050 & 0.063 & 0.043 \\
\hline \multicolumn{2}{|c|}{ Criteria } & 0.199 & 0.099 & 0.107 & 0.083 \\
\hline
\end{tabular}
weighting of the four clusters. Each value in a matrix cell indicates the weight assigned to that specific cluster and the resulting cluster matrix was obtained.

Table 8 . Cluster matrix for the case study 
As can be observed, Human Resources actions are the actions that better contribute to satisfying the criteria. It is a bi-directional relationship, i.e. the criteria exert greater influence upon the cluster Human Resources than upon the other alternatives clusters. This conclusion strengthens the observations mentioned earlier in this paper on the need for implementing actions concerning the company's staff policies.

In line with this, we recommended the EDC company managers to pay special attention to the strategic policies related to human resources.

Prioritization of alternatives within each cluster

Regarding the Human Resources cluster, the following Rank order of its alternatives has been obtained. The index obtained is called Human Resources Index (HRI).

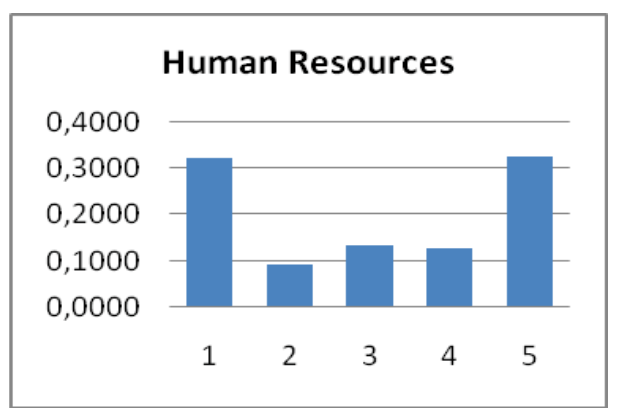

Figure 2. Results of the Human Resources alternatives

The resulting ranking of criteria in the cluster Human Resources is consistent as the two best rated alternatives (Simplify hiring processes followed by Increase head count) are consistent with managerial decisions being made in this company If the hiring process takes too long, operation executives tend to increase the number of workers via contractors or part time services to solve operational problems.

Regarding the alternatives in the Technical cluster, the following Rank order has been obtained. The index obtained is called Technical Index (TI).

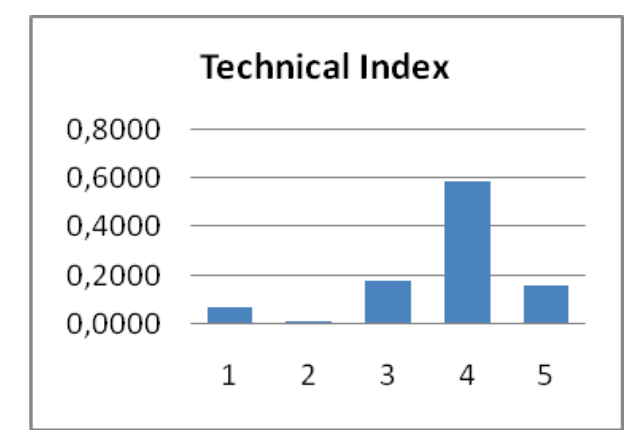

Figure 3. Results of the Technical alternatives

For this cluster, it is generally accepted among operation engineers that automation is a good way of simplifying system failure detection and solving, and this has actually been the best ranked solution.

Regarding the alternatives within the Quality cluster, the following Rank order has been obtained. The index obtained is called Quality Index (QI).

With this detailed study the EDC managers can more clearly analyze how to invest their budget within each of the three strategic lines. 


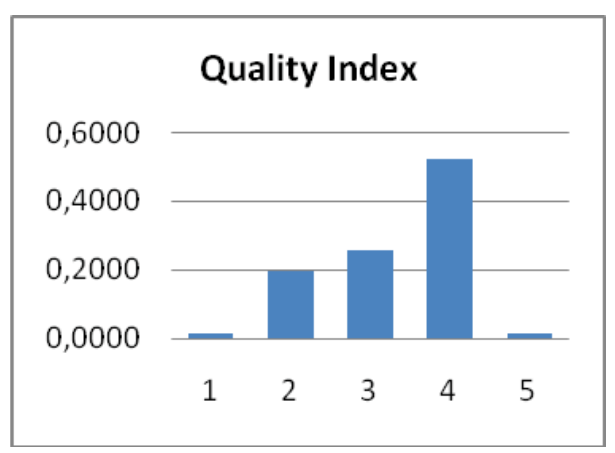

Figure 4. Results of the Quality alternatives

Prioritization of alternatives according to one single criterion

The influential relationships between the alternatives and each criterion can also be seen in the weighted supermatrix (Table 5). In other words, the PSI of each improvement project considering one particular criterion without considering the dependencies among criteria. This is the way some other MCDA techniques such as the weighted sum or the AHP, proceed. For example, for the case of service quality, the partial results are:

\begin{tabular}{|l|c|}
\cline { 2 - 2 } \multicolumn{1}{l|}{} & Service Quality \\
\hline Increase head count & 0.1044 \\
\hline Contractors' service & 0.1734 \\
\hline New technology training & 0.0205 \\
\hline Electrical training & 0.3246 \\
\hline Simplify hiring processes & 0.0000 \\
\hline Lower disconnected load & 0.0642 \\
\hline Illegal connections & 0.0000 \\
\hline Circuit transfer automation & 0.0702 \\
\hline Network automation & 0.0330 \\
\hline Locking basements access & 0.0844 \\
\hline Solution time & 0.0036 \\
\hline Supply time & 0.0317 \\
\hline Customer satisfaction & 0.0035 \\
\hline Contract awarding & 0.0000 \\
\hline Failure trip time & 0.0040 \\
\hline
\end{tabular}

Table 9. Results of the alternatives with respect to criterion Service quality

Which means:

Service Quality Indicator Increase head count $=0.1044$

Service Quality Indicator Contractors service $=0.1734$

And so on

For this particular strategic analysis the alternative Increase staff has the highest index (almost twice as high as next one) so it is by far the best. The same analysis can be carried out with the rest of the criteria. 


\subsection{Results about the criteria}

The weights of the different criteria analyzed can also be obtained.

\begin{tabular}{|l|c|c|c|}
\cline { 2 - 4 } \multicolumn{1}{c|}{} & Priority in limit matrix & Global priority & Weight (\%) \\
\hline Service Quality & 0.00066 & 0.0019 & 0.19 \\
\hline Service Continuity & 0.00144 & 0.0042 & 0.42 \\
\hline Costs & 0.10019 & 0.2899 & 28.99 \\
\hline Execution feasibility & 0.01798 & 0.0520 & 5.20 \\
\hline Investment & 0.19974 & 0.5780 & 57.80 \\
\hline Network flexibility & 0.00159 & 0.0046 & 0.46 \\
\hline Public opinion & 0.00036 & 0.0010 & 0.10 \\
\hline Company's staff & 0.00563 & 0.0163 & 1.63 \\
\hline Maintenance and servicing plans & 0.00166 & 0.0048 & 0.48 \\
\hline Response times & 0.01632 & 0.0472 & 4.72 \\
\hline
\end{tabular}

Table 10. Results for the criteria

On the other hand, the most significant criterion according to the group of experts was Investment, followed by Costs. Far behind are the rest of the criteria.

The decisions made on the Project portfolio before the application of the present case study only took into consideration the economic criterion and did not take into account other strategic issues that were important for EDC; therefore the budget was sequentially distributed between the corrective and notplanned actions to solve the failure problems that occurred in the electric power network. After the present decision analysis, the EDC managers have seen the need for making their decisions based on other criteria that influence improvement actions and better contribute to achieve EDC strategic goals. Despite this, EDC decision makers still give higher importance to the economic criteria over the other criteria. This makes sense as the financial factor is of greatest importance for the EDC managers when deciding on annual budget distribution.

The analysis of results shows that the criteria Public Opinion and Service Quality are the least important because:

- $\quad$ EDC is one of the best considered power supply companies in the country.

- The current analysis of the electric power network is performed at the primary network only.

- Service quality concerns only include actions related to voltage levels according to international standards. However, voltage recordings are only taken systematically at power distribution substations but not at the end users' meters unless they are high power consumption users.

- EDC has no Service Quality and User Opinion measurement indicators and thus the company does not consider these issues as influential. Regarding end users, there is no technology or equipment to measure electric power variables, and even when there are certain non-standardized procedures to measure Public Opinion, the indices of these two criteria are not estimated.

The next criterion in the ranking is Response Time. This can be due to the fact that the experts interviewed in the decision analysis process are operation and maintenance engineers for whom system failure identification, planning, execution and solution times are of great importance.

Of the rest of criteria we could mention the importance of the company's staff and opinion (including the decision makers) in the decision making process. The company's staff opinion will imply the failure or the success of a project. Managers recognize this in their participation on this research work.

Degree of satisfaction with the procedure 


\subsection{Degree of satisfaction with the procedure}

The experts were asked about their opinion on the decision procedure carried out with the purpose of assessing its difficulty, efficiency and satisfaction compared to the type of information and the use of resources. Opinions were gathered by means of the following questionnaire [Garcia Melon, 2008]. The following table shows the experts' average scores for each of the aspects evaluated.

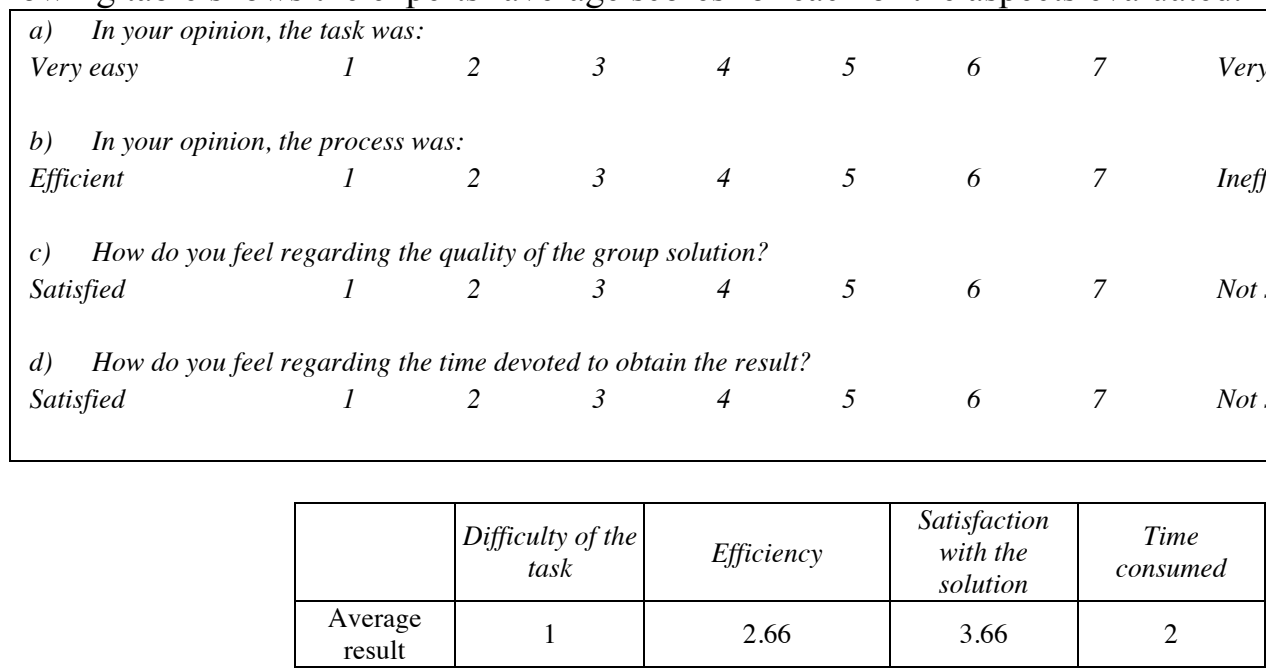

Table 11. Results of the process satisfaction questionnaires

After analyzing the results obtained in Table 11 the following can be concluded: firstly, all the scores obtained an average value lower than 4, which means that experts are satisfied with the process. However, we want to point out that the question with the worst score was the degree of satisfaction with the solution.

The experts were asked if they were satisfied with the final solution, but we must stress that the final solution of the group greatly differs from the individual solutions since some of the experts were in disagreement with certain values or ranking order of the items. However, the perception of unbiased results achieved with the proposed method allowed experts to accept the resulting criteria ranking and weights.

\section{Conclusions}

This paper presents a new approach to prioritize a project portfolio in an efficient and reliable way based on the main strategic goals of a company. The method seeks to assist managers to distribute the annual budget among the possible improvement actions to be conducted on the power network system, giving each project a relative weight.

The method presented in this paper has been applied to the proposal for improving the distribution electrical network of Caracas (Venezuela). A total of 15 network improvement actions grouped into three clusters according to the new strategic objectives of the company have been analyzed using the Project Strategic Index (PSI) proposed.

The approach is based on ANP technique. The experts have identified a total of 10 factors to be considered in the prioritization of the strategic lines of the company, which have been used as ANP criteria. By using goal-oriented questionnaires designed by the authors, the experts have determined the importance of the ANP criteria, the relationships among criteria, and the relationships between the criteria and the network improvement alternatives. 
The resulting data show that economic criteria are the most important, and the Network automation project is by far the alternative which obtains the best Project Strategic Index. According to the experts, this above mentioned first ranked action can be due to the disorganized increasing of the electrical network responding with great delay to the increasing power demand. There has not been enough time to update the complete network. It seems also logical that some of the actions with the highest PSI belong to the cluster "Human Resources" due to important changes in the company's management. This has forced EDC to adapt its human resources policies.

The experts involved in the application of the method expressed their satisfaction not only in the efficacy and traceability of the procedure but also in the results of the elaboration of the index. It is worth mentioning that they expressed such opinion even though they had to answer more than 350 questions, which took them $2 \frac{1}{2}$ hours. The experts were interviewed separately and answered the question in one session. On the other hand, they agreed in indicating the efficiency of the model compared to other conventional approaches, as it involves the use of fewer resources.

Nevertheless, as above mentioned the use of ANP is not free of criticism. In fact, during the ANP application to the case study the following difficulties were observed. Firstly, ANP prescribes comparisons that occasionally get to be complex to understand for experts not familiarized with the method. Hence, much attention must be devoted to the elaboration of the questionnaires and the comparison process must be helped by a facilitator. Besides, to arrange an experts' panel with adequate number of participants of sufficient qualification can pose the major problem of the method. Finally, ANP gets much more laborious as the number of alternatives and/or criteria grows, and therefore, it gets much more difficult to apply with rigor and efficiency.

Despite these difficulties, the results obtained in this work allow to conclude that ANP is a suitable tool for portfolio selection. It allows obtaining an index for each alternative which aggregates different information related to strategic key indicators. Although the new proposal has been specifically applied to the prioritization of project portfolio, this tool can be adapted to any type of decision-making problem, provided the criteria are correctly identified and there are some dependencies among them. This tool constitutes a very promising future research line in the field of project management.

The decision analysis approach used in the study allows project portfolio selection as this process has to be conducted every year with the participation of different actors and stakeholder in the decision-making process. Project portfolio classified by company sectors and departments can be prioritized using this methodology.

\section{REFERENCES}

Barba-Romero S, Pomerol J Ch (1997). Decisiones Multicriterio. Fundamentos Teóricos y Utilización Práctica. Universidad de Alcalá de Henares: Alcalá de Henares.

Belton V, Stewart T (2002). Multiple Criteria Decision Analysis an Integrated Approach. Kluwer Academic Publishers: London

Brams J P, Vincke P, Mareschal B (1986). How to select and how to rank projects: The PROMETHEE Method. Eur. J. Opl. Res. 24: 228238.

Buchanan J, Vanderpooten D, (2007). Ranking projects for an electricity utility using ELECTRE III. International transactions in operational research 14:309-323. 
Cheng EWL, Li H (2005). Analytic network process applied to project selection. J. Constr. Eng. Manage.-ASCE 131: 459-466.

Erdoğmuş Ş, Aras H, Koç E, (2006). Evaluation of alternative fuels for residential heating in Turkey using analytic network process (ANP) with group decision-making. Renew. Sust. Energ. Rev. 10: 269279.

García-Melón M, Aragonés-Beltrán P, González-Cruz M, (2008). An AHP-based evaluation procedure for Innovative Educational Projects: A face-to-face vs. computer-mediated case study. Omega 36- 5: 754765.

Haktanilar B (2005). Determination of the appropriate energy policy for Turkey. Energy 30:1146-1161.

Halouani N, Chabchoub H, Martel J M, (2009). Promethee-MD-2T method for project selection, Eur. J. Opl. Res. 195-3: 841-849.

Lee A H I, Chen H H, Kang H Y (2009) Multi-criteria decision making on strategic selection of wind farms. Renew. Energy 34-1: 120-126.

Meade L M, Presley A (2002). R \& D Project Selection using the Analytic Hierarchy Process. IEEE Trans. Eng. Manage. 49-1: 59-66.

Niemira MP, Saaty TL, (2004). An Analytic Network Process model for financial-crisis forecasting. International Journal of Forecasting 20: 573-587.

OPSIS, (2008). www.opsis.org.ve, accessed 15 October 2008.

Raisinghani H S, Meade L, Schkade L, (2007). Strategic e-business decision analysis using Analytic Network Process. IEEE Trans. Eng. Manage. 54 (4); 673-686.

Roy B (1996). Multicriteria methodology for decision aiding. Kluwer Academic: Dordrecht.

Saaty TL (1996). The analytic hierarchy process: planning, priority setting, resource allocation. RWS Publications: Pittsburgh.

Saaty TL (2001). Decision making with independence and feedback: The Analytic Network Process. RWS Publications: Pittsburgh.

Su C-T, Chou C-J (2008). A systematic methodology for the creation of Six Sigma projects. A case study of semiconductor foundry. Expert Syst. Appl. 34: 2693-2703.

Tavana M (2006). A priority assessment multi-criteria decision model for human spaceflight mission planning at NASA. J. Oper. Res. Soc. 57: 1197-1215.

Wey WM, Wu KY (2007). Using ANP priorities with goal programming in resource allocation in transportation. Math. Comput. Model. 46: 985-1000.

Young G O (1964). Synthetic structure of industrial plastics (Book style with paper title and editor). In Peters J (ed). Plastics 1964, 2nd ed. vol. 3. McGraw-Hill:New York, pp. 15-64. 